\title{
Jurisprudentie
}

\section{Grote schoonmaak ten aanzien van de poetsplicht?}

\section{De drie CRvB-uitspraken van 18 mei 2016 over de Wmo 2015}

\author{
Mr. dr. M.F. Vermaat en mr. C.W.C.A. Bruggeman*
}

\section{Inleiding}

Sinds 1 januari 2015 is de nieuwe Wet maatschappelijke ondersteuning (Wmo 2015) van kracht. De wet kent een aantal bijzondere aspecten. Een van de belangrijkste is wel dat de normale wijze van besluitvorming, zoals die in de Algemene wet bestuursrecht (Awb) is neergelegd, niet wordt gehanteerd. Eerst vindt in het kader van de Wmo 2015 het onderzoek plaats, na een melding ex artikel 2.3.2 Wmo 2015, en pas daarna kan de aanvraag worden gedaan. In dat onderzoek wordt getracht om zo veel mogelijk op voet van gelijkheid met de cliënt te bezien wat iemand zelf kan doen om zijn problemen op te lossen, en wat er eventueel nog door de gemeente moet worden gedaan. Bij deze manier van werken passen, aldus veel gemeenten, een open wijze van communiceren en ruim geformuleerde doelstellingen. Bijvoorbeeld dat het doel is dat iedereen in een schoon en leefbaar huis kan wonen. Wat dat dan in het concrete geval betekent, is aan de cliënt om met de aanbieder van de schoonmaakdienst te overleggen. Andere gemeenten gingen nog een stapje verder en stelden zich op het standpunt dat voor het schoonmaken van het huis alleen die mensen in aanmerking kwamen die niet zelf de regie

Mr. dr. M.F. (Matthijs) Vermaat is advocaat te Amsterdam en mr. C.W.C.A. (Kees-Willem) Bruggeman zelfstandig adviseur sociaal domein (Brug Consult) en rechter-plaatsvervanger in de Rechtbank Gelderland; beiden zijn docent Wmo aan het opleidingsinstituut voor de rechterlijke macht (SSR). over hun leven konden voeren. Met andere woorden: als je nog helemaal 'bij' bent word je geacht dat zelf te kunnen organiseren, ook al heb je geen geld.

Deze nieuwe manier van werken - en soms in feite zelfs de volledige weigering om nog hulp bij het huishouden te leveren - ontketende een flinke vloed aan bezwaar- en beroepschriften. En de nodige ontslagen in de zorgsector, boze brieven, een bezetting van het gemeentehuis in Berkelland, veel pers en een lucratief businessmodel voor een rechtsbijstandsverlener. ${ }^{1}$ Op 23 maart 2016 vond de eerste zitting van de Centrale Raad van Beroep (CRvB) over de Wmo 2015 plaats en op 18 mei 2016 volgden de uitspraken. ${ }^{2}$ Hieronder gaan wij in op een aantal belangrijke elementen in deze uitspraken. Er is nog geen nieuw beleid van de desbetreffende gemeenten bekend, maar er is wel een ledenbrief van de Vereniging Nederlandse Gemeenten (VNG). ${ }^{3}$ Daarop zal voor zover mogelijk worden ingegaan. ${ }^{4}$

1. Uitspraak inzake rechtshulpverlener die $€ 121.000$ aan vergoeding kos ten rechtsbijstand toucheert ECLI:NL:RBGEL:2016:3933.

2. ECLI:NL:CRVB:2016:1402-1404, AB 2016/202-204, m.nt. C.W.C.A. Bruggeman, Gst. 2016/99, m.nt. H.F. van Rooij, RSV 2016/106-108, m.nt. H.F. van Rooij en C.W.C.A. Bruggeman en USZ 22016/208-209, m.nt. M.F. Vermaat.

3. vng.nl/files/vng/brieven/2016/20160720_ledenbrief_reparatie-mogelijkheden-ivm-de-wmo-uitspraken-van-de-crvb-van-18-mei-2016.pdf.

4. De verwijzingen naar rechtsoverwegingen in dit artikel hebben betrekking op ECLI:NL:CRVB:2016:1402, tenzij expliciet anders aangegeven. 


\section{Valt poetsen onder de Wmo?}

Het meest in het oog springende onderwerp was ongetwijfeld de vraag of eenvoudige hulp bij het huishouden (hierna kortweg: $\mathrm{HbH}$ ) nog onder de reikwijdte van de Wmo 2015 valt. Veel gemeentebesturen vonden van niet, waarschijnlijk mede ingegeven door de door het ministerie opgelegde, vergaande bezuinigingen. De meeste rechtbanken, waaronder Rechtbank Gelderland, deelden deze opvatting niet. ${ }^{5}$ Rechtbank Zeeland-WestBrabant kwam daarentegen tot een tegenovergesteld oordeel. ${ }^{6}$ De uitspraken brachten ook heel wat juridische auteurs in beweging. ${ }^{7}$ Opvallend is dat geen enkele auteur uiteindelijk de opvatting van Rechtbank ZeelandWest-Brabant deelde, hoewel daar grammaticaal best iets voor te zeggen was. De veel meer op de bedoeling van de wetgever, zoals blijkend uit de parlementaire geschiedenis, en de maatschappelijke context van de Wmo 2015 (te weten extramuralisering) stoelende uiteenzetting van Rechtbank Gelderland vond vooral bijval.

Dit brengt meteen het eerste kritiekpunt op de kwaliteit van de Wmo 2015 voor het voetlicht. Het is bedenkelijk als een fundamenteel onderdeel van de wet - het gaat hier immers niet om een detailvraag - in de rechtspraak tot een volstrekt tegenovergestelde uitleg leidt.

In de zaken waarover de Raad uitspraak deed, stond in geen van alle de vraag of $\mathrm{HbH}$ onder de Wmo 2015 viel ter discussie. Dat de Raad deze toch aan de orde heeft gesteld roept wellicht, gelet op artikel 8:69 Awb (omtrent de grenzen van het geschil), vragen op. Het gaat echter om een bevoegdheidskwestie. Zou het antwoord op de vraag 'nee' zijn, dan zou men zich tot de verkeerde appelrechter hebben gewend. ${ }^{8}$ Hoewel niet met zoveel woorden uitgesproken, zegt de Raad hier in feite dat het wél onder de reikwijdte van de Wmo 2015 brengen van de hulp bij het huishouden, indien hiertoe geen wettelijke verplichting zou bestaan, zou dienen te worden beschouwd als een te breed opgevatte opdracht tot het stellen van regels in medebewind. Dat zou dan tot de conclusie moeten leiden dat voor dat onderdeel van de lokale regels de Afdeling bestuursrechtspraak van de Raad van State bevoegd zou zijn, omdat dat onderdeel te beschouwen zou zijn als een autonome verordening in de zin van de Gemeentewet. Misschien een wat gekunstelde redenering, maar hiermee kon wel direct een klip en klaar antwoord op de vraag worden gegeven of $\mathrm{HbH}$ onder de Wmo 2015 valt of niet, zonder dat partijen deze stelling hadden betrokken. Over het antwoord op de vraag doet de Raad niet zo lang. Daar waar

. Zie voor de annotaties Gst. 2016/45 en 46 (m.nt. bij beide uitspraken van H.F. van Rooij), RSV 2016/38 en 52 (m.nt. bij beide uitspraken van D. Last en E. Boersma), USZ 2016/40 (alleen bij Rb. Zeeland-West-Brabant, m.nt. M.F. Vermaat) en JG 2016/5 (alleen bij Rb. Gelderland, m.nt. E.E. Schaake).

8. Zie r.o. 5.6.1 de rechtbanken zich nog uitputten in analyses om deze vraag positief of negatief te beantwoorden, zegt de Raad in r.o. 5.6.1 onder verwijzing naar de diametrale opvattingen van de twee rechtbanken simpelweg het volgende:

'(...) De Raad beantwoordt deze vraag bevestigend. De wetsgeschiedenis bevat geen enkel aanknopingspunt dat de wetgever op dit punt heeft willen breken met de Wmo en evenmin dat het voeren van een gestructureerd huishouden als bedoeld in artikel 1.1.1 van de Wmo 2015 niet mede de zorg voor het schoon en op orde houden van het huishouden zou omvatten, alsook de zorg voor het kunnen beschikken over schoon beddengoed en schone kleding.'

De motivering kent een hoog gehalte aan 'hiermee hakken we de knoop door'. Want zo duidelijk was het nou ook weer niet, maar als hoogste rechter kun je dat nu eenmaal. ${ }^{9}$ De bijna verzuchtende toon van waar toch al die twijfel of ophef vandaan komt, valt wel op. Met name de VNG kan zich dit aantrekken, want zij was de grote voorstander van de beperkende lijn, waaraan veel gemeenten gevolg hebben gegeven. Tegelijkertijd moet wel opgemerkt worden dat de VNG niet de volledige nullijn heeft bepleit. De VNG schreef al in $2013^{10}$ :

'Het feit dat de HH in de Wmo 2015 niet meer voorkomt betekent niet dat de gemeente $\mathrm{HH}$ niet meer hoeft in te zetten als na onderzoek blijkt dat dit de meest passende oplossing in een individuele situatie is.'

Ook voor de VNG was het blijkbaar op zichzelf wel duidelijk dat, zoals de CRvB dat formuleert, er geen enkel aanknopingspunt is dat de wetgever heeft willen breken met de 'oude' Wmo. Staatssecretaris Van Rijn (VWS) heeft overigens ook niet nagelaten om dit te benadrukken:

'Het kan niet zo zijn dat gemeenten dit niet meer aanbieden. Als huishoudelijke hulp voor een burger passende ondersteuning is moet de gemeente dit bieden. Als blijkt dat gemeenten hier wel mee stoppen, dan zal ik de gemeente daarop aanspreken.' (Handelingen II 2014/15, 27, 6)

\section{De wegen naar Rome}

Gemeenten hebben ingevolge de Wmo 2015 een grote beleidsvrijheid. Zie de artikelen 2.1.2 (inzake de opstelling van een beleidsplan) en 2.1.3 (inzake de opstelling

9. Overigens sluit deze korte maar krachtige standpuntbepaling inhoudelijk wel het beste aan bij de benadering van Rechtbank Gelderland.

10. De Vereniging Nederlandse Gemeenten (VNG) heeft, zoals het een belangenorganisatie betaamt, haar leden van advies gediend. Op 16 oktober 2013 schreef de VNG daarom een ledenbrief (vng.nl/files/vng/ brieven/2013/lbr.pdf) waarin suggesties werden gedaan om de schade te beperken. 
van een verordening). Met die beleidsvrijheid moeten gemeenten zich echter niet rijk rekenen. Die heeft namelijk alleen betrekking op het hóe, niet op het of maatschappelijke ondersteuning dient te worden geboden. Hoe het doel beleidsmatig wordt nagestreefd is een bestuurlijke/beleidsmatige keuze en dan past de bestuursrechter slechts terughoudendheid (marginale toetsing).

Maar hoe zit dat als de rechter de in het individuele geval genomen beslissing gaat toetsen? Wat betekent de zinsnede 'naar het oordeel van het college' in artikel 2.3.5, lid 3, Wmo 2015 in dit verband? Diezelfde bepaling heeft het ook over een passende bijdrage aan de zelfredzaamheid of de participatie van de cliënt. De CRvB in r.o. 5.7.3:

'(...) Indien het gemeentebestuur in redelijkheid tot het beleid heeft kunnen komen, zal dat het uitgangspunt zijn bij het beantwoorden van de vraag of de in geschil zijnde maatwerkvoorziening een passende bijdrage levert aan de zelfredzaamheid of participatie van de cliënt. Het is in laatste instantie aan de bestuursrechter om in een voorkomend geval tot het oordeel te komen dat een in overeenstemming met het beleid toegekende maatwerkvoorziening geen passende bijdrage levert als bedoeld in artikel 2.3.5, derde lid, tweede volzin, van de Wmo 2015. (...)'

Dat wil zeggen dat, daar waar het beleid de marginale toetsing doorstaat en een besluit in overeenstemming daarmee wordt genomen, een individueel besluit nog steeds onderuit kan gaan in verband met de beoordeling door de bestuursrechter als zijnde onvoldoende passend. Er moet maatwerk worden geleverd en daarbij horen standaardoplossingen niet, aldus de Raad. In een rechtstreeks aan de memorie van toelichting ontleende rechtsoverweging ${ }^{11}$ zegt de Raad het aldus:

'(...) Er bestaat dus niet één oplossing, maar er kunnen meerdere wegen naar Rome leiden. Het is aan het college, waar mogelijk rekening houdend met de redelijke wensen van de aanvrager, om te besluiten op welke wijze het de aanvrager ondersteunt en met welk pakket van de op de behoeften, persoonskenmerken en mogelijkheden van de persoon afgestemde diensten, hulpmiddelen, woningaanpassingen of andere maatregelen een passende bijdrage aan de zelfredzaamheid of participatie wordt geleverd. De verplichting om een maatwerkvoorziening te bieden gaat echter niet zo ver dat de aanvrager in exact dezelfde of wellicht zelfs betere positie wordt gebracht dan waarin hij verkeerde voor hij de ondersteuning nodig had. De gevraagde ondersteuning moet in een redelijke verhouding staan tot wat de situatie van de aanvrager was voor hij ondersteuning nodig had.' (Kamerstukken II 2013/14, 33841, 3, p. 159 en 150)
Of er marginaal of integraal wordt getoetst staat er niet met zoveel woorden, maar in de erop volgende overweging komt het wel wat meer uit de verf. Als de beleidsmatige insteek te wensen overlaat (zoals hier), dan geeft de Raad aan dat hij zelf voorziet in de zaak en daarbij aansluiting zoekt bij de vorige niet-betwiste omvang van de hulp bij het huishouden, dan wel bij de oude CIZnormen (r.o. 5.7.4). Dat duidt op vol toetsen, vinden wij, en het past in de lijn van de vorige Wmo (Wmo 2007). ${ }^{12}$ Het past ook volledig bij de basisconcepten die aan de Wmo 2015 ten grondslag liggen, te weten maatwerk, afstemming op een reeks aan feitelijke en juridische mogelijkheden met als uiteindelijk oogmerk een passend resultaat. Dan zal integraal moeten worden getoetst, zoals de regering overigens ook in voormelde memorie van toelichting bij artikel 2.3.5, lid 3 te kennen gaf:13 'De formulering van deze tweede volzin moge duidelijk maken dat het gaat om een wettelijke norm waaraan de rechter in voorkomend geval "vol" kan toetsen.'

\section{Hoe schoon is schoon?}

Het opstellen van beleidsmatige normen ter concretisering van de open wettelijke norm is op zichzelf (uiteraard) toegestaan. Maar niet elke norm haalt de rechterlijke eindstreep. In r.o. 5.7.2 refereert de Raad aan zijn eerdere rechtspraak ${ }^{14}$ waarin is neergelegd waaraan normeringen moeten voldoen. De door de gemeente gehanteerde normen doorstaan de marginale toetsing daarvan dus niet. Er moet voor de deugdelijkheid van de normen sprake zijn van 'objectieve criteria, steunend op deugdelijk onderzoek'. Overleg met aanbieders en cliëntenraden is niet voldoende. Dat het gaat om basiseisen die in feite aan elke te hanteren norm moeten worden gesteld, wordt scherp neergezet:

'(...) Dat deze uitspraken zijn gedaan onder de werking van de Wmo en niet, zoals namens de gemeente ter zitting is aangevoerd, onder de Wmo 2015, maakt niet dat het onder de Wmo 2015 te voeren beleid niet op objectief, door onafhankelijke, geen belang bij de uitkomst hebbende, derden te verrichten onderzoek zou moeten berusten. (...) $)^{15}$

12. Zoals bleek uit de eerste uitspraak ECLI:NL:CRVB:2008:BG6612, RSV 2009/24, m.nt. C.W.C.A. Bruggeman. Zie uitgebreid ook M.F. Vermaat, H.F. van Rooij en C.W.C.A. Bruggeman: 'Compensatie in de Wmo: de rechter als plaatsvervangend bestuurder?', TVGr 2010, nr. 6.

13. De staatssecretaris van $V$ en J zei in de Eerste Kamer bij de behandeling van de Jeugdwet - die qua voorzieningenstructuur erg op de Wmo 2015 lijkt - overigens dat er marginaal getoetst zou moeten worden.

14. ECLI:NL:CRVB:2015:4262, $A B$ 2016/64, m.nt. A. Tollenaar, Gst. 2016/26, m.nt. C.W.C.A. Bruggeman en H.F. van Rooij en RSV 2016/8, m.nt. C.W.C.A. Bruggeman.

15. Belangrijk is voor dit thema ook de vierde uitspraak van 18 mei, eveneens met een zitting op 23 maart. Het gaat om een uitspraak in het kader van de Wmo 2007, die echter zeer nadrukkelijk verbonden lijkt met de drie uitspraken over de Wmo 2015. Zie ECLI:NL:CRVB: 2016:1491, USZ 2016/234, m.nt. C.W.C.A. Bruggeman. 
Hier staat expliciet dat zelfs een empirisch onderzoek door het college zelf - dat overigens voor zover ons bekend tot op heden nooit werd geproduceerd op enige zitting - onvoldoende is. Het moet door onafhankelijke derden zijn opgesteld. Ten overvloede zij hier nog aan toegevoegd dat het hier gestelde ook geldt voor de eveneens van origine in de AWBZ geregelde taak begeleiding.

\section{Verhouding tussen een algemene en een maatwerkvoorziening}

In de hierboven al aangehaalde ledenbrief uit 2013 deed de VNG de gemeenten een aantal suggesties aan de hand om de opgelegde besparing van $40 \%$ te bereiken.

'Maatregel 5 - De mogelijkheden van de Wmo 2015 benutten om van de $\mathrm{HH}$ een algemene voorziening of een product in de markt te maken.'

Op grond van de oude Wmo kan dat niet, maar op grond van de Wmo 2015 wel, zo schrijft de VNG. Dat is - althans ten aanzien van de verwijzing naar de markt een merkwaardig standpunt van de VNG, gegeven het feit dat ook wordt betoogd dat $\mathrm{HbH}$ onder de Wmo 2015 thuishoort. Dan is het niet mogelijk om deze publiekrechtelijke voorziening zonder meer te 'outsourcen' en over te hevelen naar het privaatrecht. Vormgeving via een algemene voorziening is theoretisch weliswaar mogelijk, maar deze moet dan wel een echt inhoudelijke uitwerking krijgen en niet slechts een terminologische kwestie betreffen die eigenlijk neerkomt op uitvoering door een private partij, aangezien dat evenzeer een verwijzing naar de markt lijkt. De uitvoeringspraktijk kent vele voorbeelden, mede ingegeven door de regering in de memorie van toelichting. ${ }^{16}$ Duidelijk is echter wel dat daar waar een algemene voorziening volstaat, er geen maatwerkvoorziening meer behoeft te worden geboden. ${ }^{17}$ In r.o. 4.5 .3 van ECLI:NL:CRVB: 2016:1404 beschrijft de Raad aan de hand van een citaat uit de parlementaire geschiedenis ${ }^{18}$ hoe de verhouding tussen beide is.

'(...) een algemene voorziening in de daarvoor geschikte situaties een voorliggend en volwaardig alternatief is voor een maatwerkvoorziening. Of dit in een individueel geval ook zo is, onderzoekt de gemeente indien door of namens een betrokkene een melding is gedaan dat deze maatschappelijke ondersteuning nodig heeft. Een cliënt die naar het oordeel

16. Kamerstukken I/ 2013/14, 33841, 3, p. 33-34 en Kamerstukken II 2013/14, 33841, 34, p. 160.

17. In art. 2.2.3 Wmo 2015 wordt de algemene voorziening geregeld. In art. 2.3.5, lid 3, Wmo 2015 is neergelegd hoe een maatwerktoekenning tot stand dient te komen.

18. Kamerstukken I/ 2013/14, 33841, 3, p. 34. van de gemeente voor een specifieke vorm van ondersteuning gebruik kan maken van een algemene voorziening, komt dus niet in aanmerking voor een maatwerkvoorziening voor die ondersteuning.'

Dit betekent niet dat beide voorzieningen elkaar uitsluiten in de zin dat het of een algemene voorziening is óf een maatwerkvoorziening. De Raad:

'(...) De Raad leidt hieruit af dat een gemeente ervoor kan kiezen om huishoudelijke verzorging aan te bieden in de vorm van een algemene voorziening en dat deze voorziening in dat geval als basisvoorziening voorliggend kan zijn op een eventueel in aanvulling daarop te verstrekken maatwerkvoorziening indien deze noodzakelijk is voor de zelfredzaamheid van de betrokken cliënt. Door een zodanig systeem neer te leggen in de Verordening heeft de gemeenteraad niet gehandeld in strijd met de Wmo 2015.'

De aanwezigheid van een algemene voorziening op een bepaald onderdeel van de maatschappelijke ondersteuning is dus niet per definitie compenserend. Ook bij de toepasselijkheid van een algemene voorziening moet de gemeente 'onder de streep' nog steeds maatwerk leveren, want de oplossing moet op individueel niveau passend zijn. Pas dan is het een maatwerkoplossing. ${ }^{19}$ Of dat via enkel de inzet van de algemene voorziening het geval is, moet worden vastgesteld. Afhankelijk van de uitkomst van dit onderzoek zal er al dan niet een aanvulling moeten plaatsvinden door middel van maatwerk. Anders gezegd: als het confectiepak (de algemene voorziening) lekker zit, dan is het akkoord, maar als het een beetje knelt, dan dient de kleermaker het alsnog passend te maken. Zie ook de definitie van een maatwerkvoorziening in art. 1.1.1 Wmo 2015, waarin het gaat om het geheel van diensten, hulpmiddelen, woningaanpassingen en andere maatregelen.

\section{Reparatie}

Zoals hiervoor al aangegeven, heeft de VNG het voortouw genomen om gemeenten bij te staan om hun beleid alsnog 'Wmo-proof' (of 'CRvB-proof') te maken. De CRvB heeft aangegeven, zo schrijft de VNG, dat zolang het objectieve onderzoek naar de standaardmodules nog niet is afgerond, hij in zaken over huishoudelijke hulp op grond van de Wmo 2015 zelf in de zaak zal voorzien door aansluiting te zoeken bij de voorlaatste indicatie van de cliënt, dan wel bij de normen van het CIZ-Protocol Huishoudelijke Verzorging. Dit betekent niet, aldus de VNG, dat de gemeente gehouden is in alle gevallen cliënten terug te zetten naar de voorlaatste indicatie. De CRvB geeft namelijk slechts aan dat hij, daar waar objectieve normen als eerder bedoeld ontbreken, zal teruggrijpen op de laatste indicatie die tussen partijen

19. Kamerstukken // 2013/14, 33841, 3, p. 120 
niet in geding was, dan wel - bij gebreke daaraan - op de oude CIZ-normen, nu die voldoende objectief geacht zijn (zowel onder de AWBZ als onder de Wmo 2007). Wat betekent dit concreet als iemand zich meldt en zegt 'Doet u mij de oude indicatie op basis van de CIZ-normen maar terug'? Dat kan niet in algemene termen beantwoord worden. Enerzijds mag het nieuwe beoordelingskader van eigen kracht, algemene voorzieningen en sociaal netwerk namelijk gewoon toegepast worden. Maar als dat allemaal niets oplevert voor de gemeente, dan zal een terugkeer naar de oude toekenning naar ons idee toch wel erg voor de hand liggen. Een onderzoek als bedoeld in artikel 2.3.2 Wmo 2015 zal gewoon moeten plaatsvinden. Een eenvoudige afdoening door middel van toepassing van artikel 4:6 Awb, zoals Koelewijn en Wallage suggereren, ${ }^{20}$ is onzes inziens niet aan de orde, omdat een melding/aanvraag op de toekomst ziet, en niet op het verleden. Los daarvan is het vaste rechtspraak dat nieuwe jurisprudentie geen nieuw feit of nieuwe omstandigheid is in de zin van artikel 4:6 Awb.

\section{Piketpaaltjes}

De Raad slaat in ECLI:NL:CRVB:2016:1404 nog een aantal piketpaaltjes als het gaat om de definitie van wat een algemene voorziening is. ${ }^{21}$ Een aanbieder is volgens art. 1.1.1 Wmo 2015 een natuurlijke of rechtspersoon die zich jegens het college verbonden heeft tot de levering van een algemene of een maatwerkvoorziening. Bepalend is dus of er een contractuele relatie bestaat tussen de aanbieder en de gemeente. Dit betekent dan weer dat een contractuele relatie tussen een derde en de cliënt, de burger die ondersteuning zoekt, onvoldoende is om die derde tot aanbieder in de zin der wet te bestempelen. En daarmee is een dergelijke dienst geen algemene voorziening in de zin van de wet, zo concludeert de Raad. ${ }^{22}$

De gemeente die een urennorm hanteert die niet gebaseerd is op het CIZ-protocol kan het beleid repareren door dit protocol alsnog toe te passen of een onderzoek te laten uitvoeren naar het nieuwe normenkader door een onafhankelijke derde en het beleid aan te passen op basis van de uitkomsten van dit onderzoek. Ons is niet bekend of veel gemeenten een van beide mogelijkheden toepassen. Wel hebben de gemeenten Noordoostpolder en Urk de stichting De MO-zaak (voorheen CIZ MO) gevraagd zich uit te laten over de nieuwe normen. De MO-zaak heeft laten weten dat de nieuwe normering 'amper afwijkt' van de CIZ-normen, wat in feite neerkomt op ongewijzigde voortzetting van die normen. De gemeente Utrecht heeft een onderzoek uit laten voeren

20. W.I. Koelewijn en B. Wallage, 'Onrechtmatig Wmo-beleid. Wat nu?', NJB 2016, nr. 1394, p. 1974-1976.

21. Bruggeman pleitte in een noot bij ECLI:NL:CRVB:2012:BY2147 (RSV 2013/13) al eens voor een meer uniform begrippenkader.

22. Zie in gelijke zin M.F. Vermaat, E. Klein Egelink en R. Imkamp, 'De Wet maatschappelijke ondersteuning 2015: doordachte keuzes?', Gst. $2016 / 2$. naar de door de gemeente gehanteerde standaardmodule voor een schoon en leefbaar huis. ${ }^{23}$ In dat onderzoek wordt de urennorm gerelateerd aan de beschrijving van een schoon en leefbaar huis, zoals opgenomen in de beleidsregels van de gemeente Utrecht.

De VNG blijft in haar ledenbrief (zie noot 3) van mening dat resultaatgericht indiceren mogelijk blijft, maar dan moet wel aan de volgende randvoorwaarden worden voldaan:

- In de beleidsregels moeten de werkwijze en de resultaatgebieden worden opgenomen en er moet duidelijk omschreven worden wat daaronder verstaan wordt.

- In de beschikking of in de beleidsregels moeten concrete activiteiten worden opgenomen die gedaan worden om tot het gestelde resultaat te komen.

- In de beschikking moet de frequentie (het aantal keren) van de activiteiten genoemd worden.

Opvallend is dat de VNG niet het aantal uren noemt, terwijl de Raad dat in zijn uitspraak juist wel doet. Blijkbaar wil men de ruimte openhouden dat de aanbieder de uiteindelijke 'fijnafstemming' in overleg met de cliënt doet, juist omdat het resultaat telt en niet het aantal uren dat wordt gewerkt. Volgens ons is dat beleidsmatig/inhoudelijk weliswaar een begrijpelijk standpunt van de VNG, maar stelt het juridisch wel hoge eisen aan de motivering van het besluit/het ondersteuningsplan, omdat de cliënt daaruit precies zal moeten kunnen opmaken wat die aanbieder gaat doen en hoe schoon zijn huis dan wel moet zijn. Dat de VNG zich van deze valkuil bewust is, blijkt ook wel uit de ledenbrief:

'Veel gemeenten zullen hun toekenningsproces moeten aanpassen. De werkwijze zou er als volgt uit kunnen zien. Na de melding volgt het onderzoek dat resulteert in een verslag waarin globaal de geindiceerde resultaatgebieden worden beschreven. In het verslag wordt aangekondigd dat de aanbieder een ondersteuningsplan maakt. Na ontvangst van dit ondersteuningsplan beoordeelt het college dit plan en maakt de beschikking. Het plan wordt dan onderdeel van de beschikking. Het ondersteuningsplan kan het beste een door de gemeente gemaakt format zijn dat past bij het beleidskader en de beleidsregels. De beoordeling van het ondersteuningsplan is een extra stap in de toekenningsprocedure die niet mag leiden tot een overschrijding van de wettelijke termijn van 8 weken. Het format moet tevens in het bestek en de contracten worden vastgelegd.'

\section{Ten slotte}

De CRvB heeft zich danig van zijn taak gekweten en een aantal voor de praktijk belangrijke knopen doorgehakt. Menige burger zal in ieder geval enigszins opgelucht

23. KPMG Plexus en Bureau HHM, 'Normering van de basisvoorziening "Schoon Huis". Empirisch onderzoek, Eindrapportage voor de gemeente Utrecht', Amsterdam: KPMG Plexus en Bureau HHM, 2016. 
adem halen, en anderzijds zal een flink aantal gemeenten de verloven hebben ingetrokken. Maar er blijven nog vele vragen. Over het juridische vraagstuk van delegatie van bevoegdheden bijvoorbeeld. Wat moet er in de Wmo-verordening zijn geregeld en wat kan aan het college in zogenoemde 'nadere regels' worden overgelaten? Hoe hoog moet een PGB zijn? Artikel 2.3.6 Wmo 2015 lijkt op een vat vol tegenstrijdigheden. En niet in de laatste plaats: wat is de betekenis hier van het begrip 'eigen kracht'? Daarover een andere keer meer. 